\title{
Reviving a Retrospective Conversion Project: Strategies to Complete the Task
}

\author{
Jay H. Lambrecht
}

Libraries fail to complete retrospective conversion projects for a number of reasons. A long-term decline in the conversion rate may be halted or reversed once its causes are determined. Project managers should analyze production statistics and qualitative standards over the history of the project in order to pinpoint events and policies that have contributed to its declining productivity. Many online systems produce reports that can aid in making the conversion process more efficient. If qualitative standards also must be lowered in order to revive a project, the integrity of the catalog and the job satisfaction of converters must be considered.

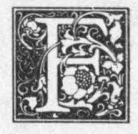

or many academic libraries, retrospective conversion seems to have moved from the temporal to the eternal plane. Library literature abounds with reports of plans, studies, and procedures for retrospective conversion projects, ${ }^{1}$ but reports of their successful completion are limited to "special libraries [and] several medium-sized academic and public libraries."'2 Despite predictions that "by the mid-1990s all but a few of the largest research libraries will have completed the conversion for their collections,",3 only 14 percent of ARL libraries were reported to have done so by April 1986. ${ }^{4}$ The same survey showed that 13 percent of respondents were not even considering conversion projects, while the remaining 73 percent "have recon plans." 5

Many libraries undoubtedly have plans that are growing old. For some, the target date for the completion of an in-house conversion project was set long ago, is now well past, and may never be mentioned again. For others, a vendor could supply most of the needed records, but the dregs remain. Still others never had a timetable for completing conversion. In each of these cases, there may be a nagging sense that the end will never come.

These facts are troubling, because it makes little sense to undertake a retrospective conversion project without intending to complete it before the millennium. Simply doing as much conversion as possible may benefit the online catalog, online circulation system, or interlibrary cooperation that conversion projects are intended to advance. But until the job is completed, the primary objectives of a library catalog are not met. Users may not be able to find a work when the author, title, or subject is known, or be able to determine all of the library's holdings by a particular author or about a particular

Jay H. Lambrecht is Catalog Librarian and Assistant Professor at the University of Illinois at Chicago, Illinios 60680. 
subject. ${ }^{6}$ Finding all of the library's holdings in one search, from wherever the computer cable or telephone line will reach, is impossible. Only a completed conversion allows for a completely functional online catalog and a fully automated circulation system.

Despite the shortcomings of partial conversion, it should not be surprising that relatively few conversion projects have been completed. Many catalog departments that undertake retrospective conversion projects get little or no additional staff to complete them, and so build (or add to already existing) backlogs of current receipts by diverting effort to conversion. In the long term, it is difficult to justify giving high priority to retrospective conversion of an item that is already cataloged instead of making a new item available for the first time. Target dates for completion of conversion projects are based on staffing levels and priorities that are bound to shift with the passing of years-and perhaps with the passage of generations of library and cataloging administrators. It is no wonder that some libraries never finish.

Some target dates for the completion of retrospective conversion projects will not go away. Projects undertaken with outside funding must meet the goals of the grant proposal and cannot afford to fail. New or remodeled libraries may not allocate valuable floor space to an obsolete card catalog, which means that conversion must be completed before a new building is occupied. Some library directors enforce a priority system that places retrospective conversion very near the top of the list. In any of these circumstances, managers of cataloging operations who need to accelerate a project are forced to do what should have been done before a crisis occurred: study the history of the retrospective conversion project, analyze the rates of productivity that have evolved over the years, determine what must now be accomplished, and manipulate qualitative standards to increase productivity so that the project might be completed on schedule.

The adjustment of qualitative standards does not mean that substandard records must be created in order to complete a major conversion project. It makes little sense to destroy the integrity of an online cata$\log$ by slapping a quick-and-dirty finish on a project that has generally been of high quality. This quick finish would be easy, but the price would be paid for decades by users who would not find what they sought and by a staff that would end up doing retrospective work in order to correct retrospective work. That is not economy. There is room to make management decisions and adjust productive norms without abandoning full bibliographic records or database integrity. The first step in this process is to analyze the history of the project to see how standards and norms have changed.

\section{ANALYSIS OF THE PROJECT'S HISTORY}

A simple division of the current rate of production into the estimated number of remaining conversions may indicate that it is necessary to rejuvenate the process in order to complete the project on schedule. If this is the case, informed decisions on how to increase the productivity of a conversion project should be based on knowledge of the project's history and evolving norms. Every library that has embarked on a conversion project should have information on how the project has progressed over the years. This mass of numbers can be analyzed and can provide important insights into evolving qualitative standards and resulting rates of productivity. For the second-generation or subsequent manager of a conversion project, this analysis is critical; for the manager who cannot recall the details of the project he or she launched long ago, it can be just as important.

Current procedures and results can be put into proper perspective if an examination of the history of a conversion project is undertaken first. Qualitative standards and quantitative norms grow out of the expectations of project organizers and are based on the needs that they perceive. Over time, needs and expectations evolve, but corresponding procedures and policies may not. The result can be a project whose focus is not on satisfying 
current needs, but the needs of five or ten years ago. For this reason, it can be profitable to examine predictions and local processing history before turning attention to the analysis of quantifiable results.

Predictions of project results may, in retrospect, be extremely optimistic. They should not be discounted, however, because they can serve as a valuable indicator of what the project was intended to accomplish. The projected norms should have been based upon knowledge of the quantifiable results of other functions of the catalog department and upon a set of qualitative standards that were assumed to be appropriate to the task. The projected norm may have been twenty conversions per hour, but the project may be producing only five conversions per hour. If so, it is clear that either the original projections were terribly erroneous or the fundamental assumptions of the project have changed. An investigation of the available data should provide the answer.

It is possible that an examination of the historical data concerning a retrospective conversion project will clarify the driving force behind the original project plan. It should not be uncommon to discover that a conversion project was begun to create and support an online circulation system, since many libraries had online circulation systems before they envisioned an online catalog. Discovery of circulation data in retrospective conversion files is good evidence of this situation. Such libraries may still be working under policies and procedures that were intended to support circulation, but are inappropriate to support an online catalog. The methods that would contribute to efficient processing for a catalog do not necessarily serve circulation, so method and object may now be at odds. Random conversion on demand based on circulation may be the practice, but systematic conversion may be the more efficient means to build an online catalog. Knowledge of the history of a project can help to uncover such problems.

The most important numbers available to the manager trying to rejuvenate a conversion project are clearly the evolving quantitative norms. These are, by definition, standards of achievement derived from the average achievement of a large group. If the number of conversions and the number of hours devoted to the task can be determined, a rate of conversion can be calculated for any particular month or year. For many projects the norm will have declined over the years. If there are periods of steep decline, concurrent events may help to define the problem. If the decline has been almost imperceptably gradual, a study of the evolving qualitative standards may provide an answer. In either case, the numbers must be analyzed in detail if the project is not to become perpetual.

\section{FACTORS IN FAILURE}

The factors that cause productive norms of a conversion project to fall can be nearly as numerous as the number of libraries still working on such projects. There are five that may be more common than the rest, however. These are:

1. The easy titles are already done. As predictions are not met and proposed deadlines pass, there is a tendency to do the easy items first. Books with Library of Congress-produced MARC records are done early; nonbook materials without records in the bibliographic utilities are put aside. In the end, difficult items must be dealt with. Productivity declines.

2. The online catalog is implemented. If a library has not completed its conversion project by the time its online catalog is brought up, its new conversions begin to appear quickly (or instantly) online. Users may see and use the records at the moment they are created, and no vendor will come along to make sure that headings do not conflict with those already in the cata$\log$. More care must be taken, and productivity declines.

3. Standards proliferate. External influences may range from OCLC Enhance Library status to NACO participation. Internal influences may be a desire to document each unusual situation so that a second decision need not be made on the same question. In the former case, more time is spent on each conversion to assure that the highest qualitative standards are met. In the latter case, productive norms are lowered as documentation is contin- 
ually revised and consulted.

4. The wrong function is being served. As in the case of a project devised to serve circulation but now intended to build a complete online catalog, serious inefficiencies may result.

5. Authority work becomes part of the process. Not only must conflicts be avoided in an online catalog, but authority records and a syndetic reference structure must be created. Circulation systems are not concerned with authority structures; neither are converters who know that a vendor will address this problem before the online catalog is implemented. Once conversion is being done into an online catalog, authority work can slow the process significantly. A survey conducted in 1984 revealed that authority work can take up to 40 percent of the time devoted to copy cataloging. ${ }^{7}$ Because conversion should be a more economical activity than copy cataloging (such tasks as book handling and shelf listing are not usually involved), authority work could consume an even higher percentage of a converter's time.

\section{SOLUTIONS}

The first two of these factors can be avoided only if they are understood very early in the project. Once the decision has been made to increase productivity by skipping over difficult titles, a corresponding decrease in production can be expected later in the project. The easy titles will be remembered fondly, but they will be gone.

Similarly, if a conversion project has not been completed before the online catalog is ready to be implemented, a drop in productivity will follow implementation. The ability of an online catalog to make bibliographic resources available instantly, both within and beyond the library's walls, cannot be changed. Those who are seriously interested in serving library patrons will not regret that they have an online catalog, but they may regret that they did not complete conversion before the online catalog was implemented.

The third through the fifth factors can be controlled in the interest of higher productive norms. Two require an adjustment of vision, while the last may require an ad- justment of work flow.

Local standards that proliferate in the interest of consistency and quality are difficult to condemn or eliminate. They are established with the intention of providing library users with the best possible bibliographic record, which is the catalog department's reason for being. When conversion production falls to unacceptably low levels, however, it is important to recognize that five "perfect" conversions might not help users as much as twenty very good conversions. Retrospective conversion projects can become, by degrees, recataloging projects. The reexamination of every aspect of a record at the time of conversion may be a luxury that cannot be afforded if the project is ever to be completed.

Similarly, if a catalog department is engaged in activities that contribute to the quality of national bibliographic or authorities databases, it is clearly engaged in worthwhile activities. Production may fall to unacceptable levels because older bibliographic records in OCLC are being enhanced or because the name and series headings in those records are being examined in preparation for submission of records to NACO. The library must recognize the cost to the conversion effort of participation in such programs and may reasonably conclude that enhancements to national bibliographic and authority databases must be limited to newly cataloged titles. Rates of conversion will rebound accordingly.

An examination of the history of a faltering conversion project may reveal that its purpose has changed over time. If this is the case, it is necessary to determine whether or not policies, procedures, and standards have evolved with it. A conversion project that was designed to be circulation based and random may not be as efficient as one that is designed to be performed systematically. The adjustment in vision that is necessary to improve quantitative norms in this case must be shared by several departments. If the most efficient means of completing an online catalog is systematic conversion, the circulation department must agree to forgo on-demand conversions that might be more useful to it in the short term. If the 
online system is integrated and will serve circulation functions, it may not be difficult to agree that the longer-term interests of both departments are served better by finishing the project quickly than by focusing on unconverted circulating titles.

Attention to authority work has the greatest potential for slowing the rate of conversion. Because retrospective conversion deals with older materials, which were cataloged according to the dictates of pre-AACR2 cataloging codes and early editions of Library of Congress Subject Headings, each heading must be checked to be certain that its addition to the online catalog will not put it in conflict with newer cataloging. If a conflict is discovered, headings frequently are not found in either the local online authority file or in LC's online authority files. The conflict must be resolved before conversion can take place if the integrity and predictability of the online catalog are to be preserved. The converter may be trying not to recatalog but is forced to make decisions and do work that is akin to cataloging.

In the case of many online catalogs, checking headings for conflicts and creating authority records in support of conversion can be greatly reduced by employing the capabilities of the online system. Some systems generate batch reports of all new headings, or of new headings that match references in authority records. Such lists alert the catalog department to names or subjects that are new to the file or that conflict with authorized forms. They are an effective means of highlighting potential conflicts that may require authority work, and save the converter from checking every added heading for consistency with existing bibliographic and authority records. An authorities unit that is dedicated to the task of checking such lists and creating authority records may already exist and be able to absorb this work. Rates of productivity for retrospective conversion should rise accordingly and allow the library to enter the conclusive stage of its conversion project.

\section{STAGES OF CONVERSION}

It is possible to define three stages of retrospective conversion in libraries that have undertaken a long-term project. The first stage is one of early enthusiasm, high productivity, and the tendency to skip over problems. Qualitative standards are very simple, because high productivity is the primary objective. A significant number of staff hours are devoted to the project, and progress is clear and encouraging. The project is seen as something clearly separate from ordinary cataloging functions and is expected to be finite.

The second stage is reached when project participants discover that optimistic projections will not be met. Early enthusiasm wanes, and fewer staff members may be devoted to the project. Problems can no longer be skipped over. A sense of failure may be overcome by an attempt to achieve legitimacy. Qualitative standards are issued to document the treatment of unusual situations. Project staff begin to see their jobs as equivalent to those of catalogers. If old local cataloging can be improved, converters want to do it. If the national database can be improved, converters want to do it. If authority work is necessary, converters want to do it. Productive norms fall accordingly.

If a library recognizes that it has slipped into this stage, a third stage is possible. It is a stage of compromise, based on reevaluated qualitative standards and adjusted quantitative norms. It is marked by high but realistic expectations for output, with standards lowered enough to allow for more progress, but still high enough to produce good records and job satisfaction.

It is on this question-the level of job satisfaction-that the ability to resurrect a failing conversion project may rest. The potential to lose good employees must be balanced against the potential to convert more records. Pride in work is to be valued, and vacant positions or low morale do not contribute to efficiency any more than unnecessarily high standards do. Authority work may have become the most vital and challenging aspect of a converter's job. Without it, the converter may feel the task has become more clerical and less satisfying. As a manager, it is important to balance a good worker's desire to perform against the need to improve productive norms and to factor in the willingness to risk losing the worker to a potentially more rewarding job. Ultimately, it is 
vital to convince the conversion staff that the end of the project really is in sight, that their legitimacy and their job satisfaction must come from the successful completion of the project, and that there is always another project awaiting their skills.

\section{CONCLUSION}

Statistics can be very usefully employed in the management of a retrospective conversion project, especially if the project has suffered a serious decline in productive norms. Statistical analysis of the project's history can allow managers to pinpoint the events that have led to a sudden decline or to document a fall that has been almost too gradual to notice. Qualitative standards almost certainly have evolved to a higher level since the inception of the project. These can be adjusted, new productive norms can be determined, and further adjustments can be made and measured as necessary. The human factor of job satisfaction for converters must enter into this equation.

It is probably not possible to achieve the optimistic norms that were predicted before a conversion project began or to reestablish the norms set early in the project. But by considering and managing all factors it may be possible to double or even quadruple the current rate of conversion. This may allow the project to be completed well before the new century dawns.

\section{REFERENCES AND NOTES}

1. The reader is referred to two compilations: Anne G. Adler and Elizabeth A. Baber, eds. Retrospective Conversion: From Cards to Computer (Ann Arbor, Mich.: Pierian Press, 1984) and Retrospective Conversion in ARL Libraries, SPEC Kit 130 (Washington, D.C.: Association of Research Libraries, 1987). See also the books and articles referring to retrospective conversion in C. Donald Cook and Ellen Jones, "Descriptive Cataloging: A Selected, Annotated Bibliography, 1984-1985," Library Resources \& Technical Services 30:248-60 (July/Sept. 1986).

2. Jutta Reed-Scott, "Retrospective Conversion: An Update," American Libraries 16:694-98 (Nov. 1985).

3. Ibid.

4. Jutta Reed-Scott, "1986 Questionnaire on Retrospective Conversion: Preliminary Analysis of Results," Retrospective Conversion in ARL Libraries, SPEC Kit 130 (Washington, D.C.: Association of Research Libraries, 1987), p.3.

5. Ibid.

6. Charles A. Cutter, Rules for a Dictionary Catalog (Washington, D.C.: Govt. Print. Off., 1904).

7. Judith Hudson, "Copy Cataloging Activities: Report of a Survey," Cataloging \& Classification Quarterly 7:63-67 (Fall 1986). 